\title{
Influence of Weld Repair by Gouging on the Residual Stresses in High Strength Steels
}

\author{
Arne Kromm ${ }^{1, a}{ }^{*}$, René Schasse ${ }^{2, b}$, Ping $\mathrm{Xu}^{1, \mathrm{c}}$, Tobias Mente ${ }^{1, \mathrm{~d}}$ and \\ Thomas Kannengiesser ${ }^{1, \mathrm{e}}$ \\ ${ }^{1}$ Bundesanstalt für Materialforschung und -prüfung (BAM), Unter den Eichen 87, 12205 Berlin, \\ Germany \\ ${ }^{2}$ Schweißtechnische Lehranstalt Magdeburg GmbH, An der Sülze 7, 39179 Barleben, Germany \\ aarne.kromm@bam.de, bschasse@sl-magdeburg.de, ${ }^{\text {c}}$ ping.xu@bam.de, \\ dobias.mente@bam.de, ethomas.kannengiesser@bam.de
}

Keywords: Repair Welding, Weld Residual Stress, Carbon Arc-Air Gouging

\begin{abstract}
Carbon arc-air gouging is a common technology when repairing defects in welded structures. Often this technique is applied in repeated cycles even on the same location of the joint. Due to the multiple heat input by gouging and subsequent re-welding, the residual stresses are strongly influenced. This can become crucial when microstructure and mechanical properties are adversely affected by multiple weld reparations. Knowledge about the relation of gouging and residual stresses is scarce but important when high strength steels, which are sensitive to residual stresses, are processed. The present study shows the effect of repair welding on a high strength steel structural element. The weld and the heat affected zone were subjected to multiple thermal cycles by gouging and subsequent repair welding. The residual stresses were determined by X-ray diffraction at different positions along the joint. The results showed that the residual stress level has increased by the repair cycles. This is most pronounced for the heat affected zone. Adapted welding procedures may prevent detrimental residual stress distributions.
\end{abstract}

\section{Introduction}

During fabrication of steel components, non-destructive testing for quality control is frequently applied. Emerging failures are often treated locally by repair welding. In this case, multiple repair cycles may be required to completely remove the failure. Standards do not limit the number of such repair cycles. Therefore, it is unknown how the number of repair cycles influences the mechanical properties and residual stresses. These stresses become important when high strength steels are applied, which are more sensitive to residual stresses due to their limited ductility.

For the removal of weld defects, carbon arc-air gouging is a commonly used method during fabrication. The advantage is the excellent failure finding ability due to the good accessibility even in the edges of a component. Carbon arc-air gouging uses a copper covered graphite electrode. Typical diameters are 6,8 or even $10 \mathrm{~mm}$. A positive polarity is used for the electrode when gouging steel. The specific current load reaches from $10.5 \mathrm{~A} / \mathrm{mm}^{2}$ for a $6 \mathrm{~mm}$ diameter electrode to $7.5 \mathrm{~A} / \mathrm{mm}^{2}$ for a $10 \mathrm{~mm}$ diameter electrode. The molten material is blown out of the weld by an air stream. The gouging depth is controlled by the angle of approach which is usually between $30^{\circ}$ and $45^{\circ}[1-2]$.

Residual stresses in repair welds are not reported in the literature up to now. Similar behavior may be expected from slit welds which are used to evaluate the cold cracking behavior of welds. The notch created by gouging is comparable to the slit used in specific tests [3-7]. Published data reveals that the residual stresses in such tests are influenced by slit characteristics, i.e. length [3-4] and position in the sample [8-9], and the stiffness (restraint intensity) of the test pieces [5]. Nevertheless, the number of gouging and respective repair welding cycles has not been investigated yet. Therefore, the present work focuses on the residual stress development considering multiple repair cycles.

(c) (1) Content from this work may be used under the terms of the Creative Commons Attribution 3.0 license. Any further distribution of this work must maintain attribution to the author(s) and the title of the work, journal citation and DOI. Published under license by Materials Research Forum LLC. 


\section{Experimental}

The sample for residual stress analysis was adopted from a typical detail in a real bridge construction (Fig. 1, left). The lower flange joint of the cross girders of an open bridge deck and the orthotropic plates are static sensitive joints. In service, the load acts transverse to the weld. The weld is under tensile stress. In case of railway bridges, this type of joint is therefore checked $100 \%$ by nondestructive testing.

In this study, the test sample consisted of two base plates acting as the lower flange of the main beam, namely the cross girder. The transverse stiffener, located on the root side of the weld, simulated the cross-girder web (Fig. 1, right).

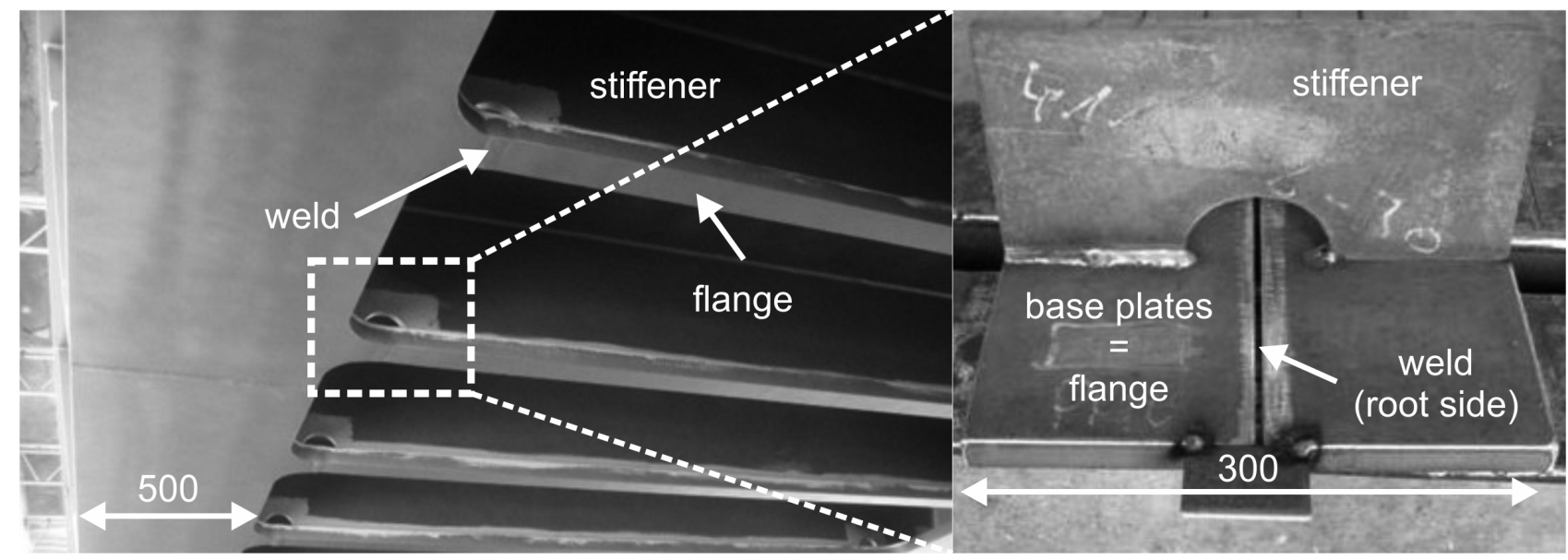

Figure 1: Weld detail in a bridge construction - cross girder joint (left), sample simulating the cross girder joint consisting of two base plates and a transverse stiffener on the root side (right)

Welding was performed according to typical parameters used during fabrication as indicated in Table 1. Two base materials with a thickness of $20 \mathrm{~mm}$ (base plates) and $10 \mathrm{~mm}$ (stiffener) were chosen. The high strength steels S355J2+N and S690QL (minimum yield strength: $355 \mathrm{MPa}$ respectively $690 \mathrm{MPa}$ ) were welded using gas metal arc welding (GMAW). Matching filler materials G3Si and G69 $4 \mathrm{M}$ Mn3Ni1CrMo were used with $1.2 \mathrm{~mm}$ wire diameter, in accordance to ISO 14341 and ISO 16834-A.

Table 1: Welding parameters

\begin{tabular}{|l|l|l|l|l|l|}
\hline Layer & $\begin{array}{l}\text { Preheat/interpass } \\
\text { temperature }\left[{ }^{\circ} \mathrm{C}\right]\end{array}$ & Current [A] & Voltage [V] & $\begin{array}{l}\text { Welding speed } \\
{[\mathrm{cm} / \mathrm{min}]}\end{array}$ & $\begin{array}{l}\text { Heat input } \\
{[\mathrm{kJ} / \mathrm{cm}]}\end{array}$ \\
\hline Root & 120 & $250-260$ & $28-29$ & 35 & 12.45 \\
\hline Intermediate & 200 & $300-310$ & $31-32$ & 42 & 13.73 \\
\hline Top & 200 & $280-290$ & $29-30$ & 27 & 18.68 \\
\hline
\end{tabular}

A carbon electrode with a diameter of $6 \mathrm{~mm}$ at a current of 380-400 A was applied for gouging in each case. It was performed over a length of $200 \mathrm{~mm}$ located on the top surface of the weld according to Fig. 3. During each repair cycle the weld seam was not removed completely. A small edge of the original weld seam with extent of 1-2 mm was left. After the initial welding cycle and between, the joints were allowed to cool down to ambient temperature. Gouging and subsequent repair welding was repeated up to five times. The depth of the gouged region was about $7 \mathrm{~mm}$. 

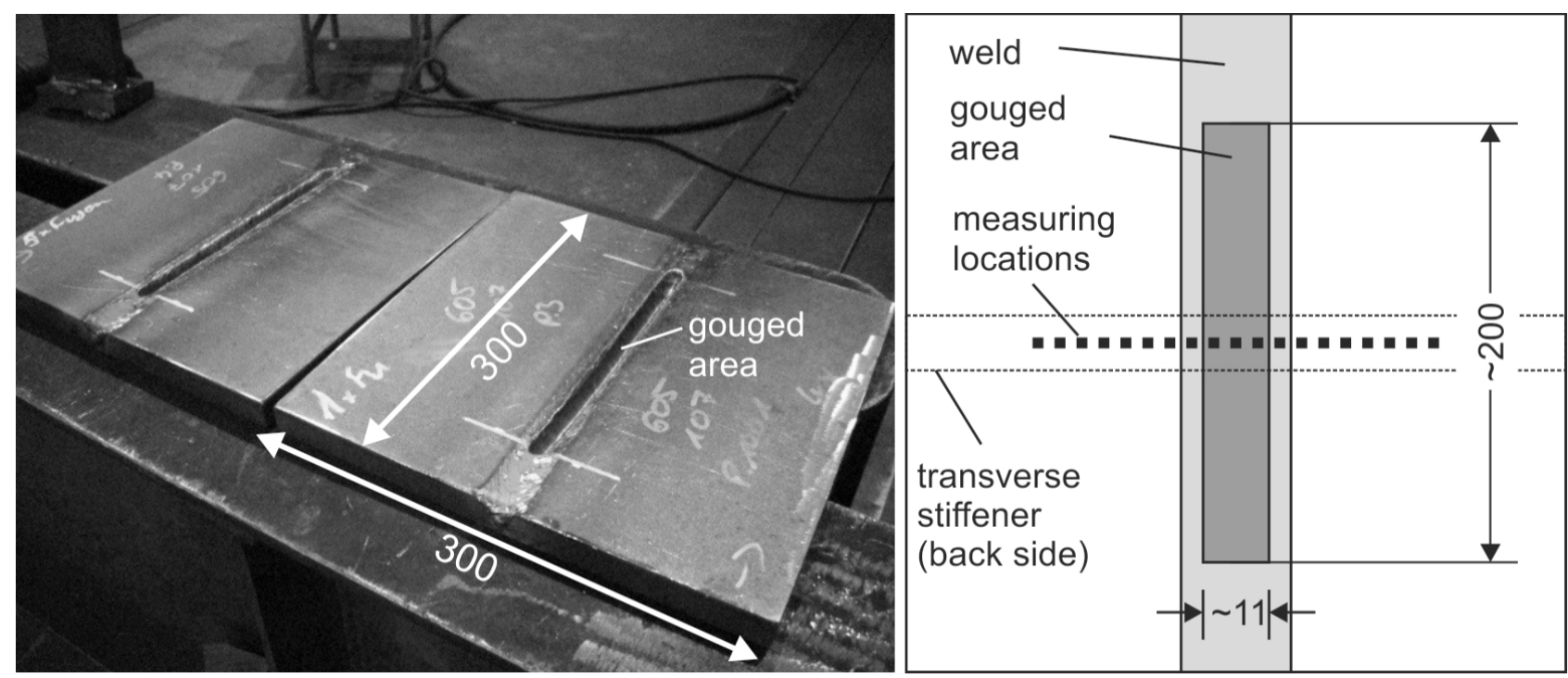

Figure 2: Gouged test samples (left), location for residual stress determination on sample top surface indicated by black dotted line (right)

The residual stresses were determined by X-ray diffraction using the $\sin ^{2} \psi$-method [10]. Measuring and evaluation parameters are given in Table 2. The measurements were performed along the line located in the center on the top surface of the joint covering the weld, HAZ and base material. 25 points were chosen along a distance of $48 \mathrm{~mm}$. Fig. 2 (right) shows the location and arrangement of the residual stress measurement. There are single locations in the weld and also HAZ where the residual stresses could not be determined due to microstructural reasons (nonlinear $\mathrm{d}$ vs. $\sin ^{2} \psi$ distributions).

Table 2: Measuring and evaluation parameters for residual stress analysis

\begin{tabular}{|l|l|}
\hline Measuring mode & $\sin ^{2} \psi$ \\
\hline Focus & $2 \mathrm{~mm}$ \\
\hline Radiation & $\mathrm{CrK \alpha}$ \\
\hline Diffraction line & Ferrite: 211 \\
\hline $\mathrm{E}\{211\}$ & $211.000 \mathrm{MPa}$ \\
\hline$v\{211\}$ & 0.3 \\
\hline
\end{tabular}

\section{Results and Discussion}

Residual stresses found for the as welded condition in the samples of steel S355 (see Fig. 5 left) showed higher values for the longitudinal direction as compared to the transverse one. This accounts for the weld metal itself and also for the heat affected zone (HAZ) in the base material. The highest peak values may reach the yield point of the steel. The transverse direction is characterized only by moderate tensile stress levels not above $150 \mathrm{MPa}$. The stress level and distribution is mainly influenced by the restrained shrinkage of the weld and HAZ.

The S690 shows comparable residual stress characteristics (Fig. 5 right), although the highest stress peaks, which were found only in the HAZ, had values up to $250 \mathrm{MPa}$. The weld metal showed lower stresses, which were caused by the phase transformation to bainite and martensite [11]. Even compressive residual stresses may appear. 

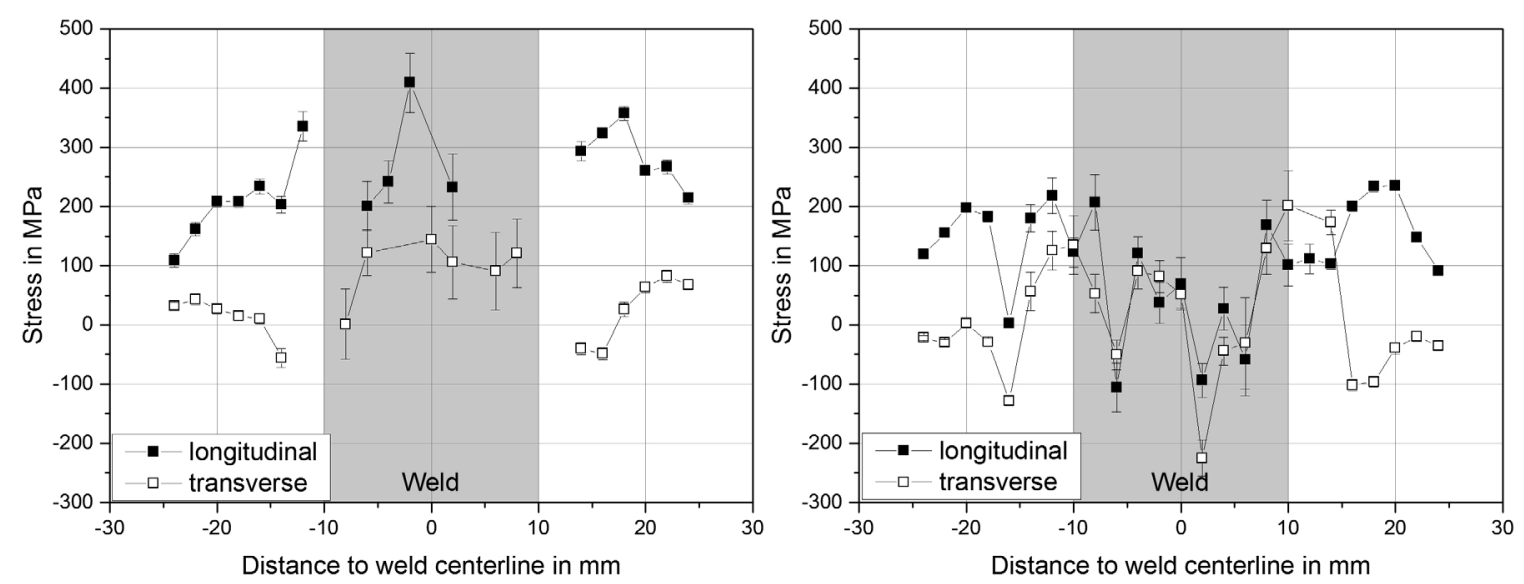

Figure 5: Longitudinal and transverse residual stresses in the as welded condition of S355 (left) and $S 690$ (right)

After the first repair cycle the residual stresses in S355 were shifted to higher values, especially in the HAZ and the base material. The weld metal showed more or less the same characteristics as found for the as welded condition. In the HAZ particularly, the transverse residual stresses were affected by the repeated heat input due to the deposition of the weld metal. The same trend was observed for the higher strength material S690 (Fig. 6, right). While the weld metal was less affected, the HAZ and the base material showed elevated tensile residual stresses around $400 \mathrm{MPa}$. The stress distribution appeared asymmetric, due to manual welding and gouging. The main reason for the residual stress rise after the first repair cycle was the increase of the shrinkage restraint due to the notch resulting from gouging. Applying a number of repair cycles to the same weld led to even higher stress levels which reached the yield strength, particularly in case of S355 (Fig. 7, left). The weld metal of S690 was less affected, due to the stress reduction caused by the phase transformation, (Fig. 7, right). Nevertheless, the HAZ showed increased residual stress levels with repeated gouging.
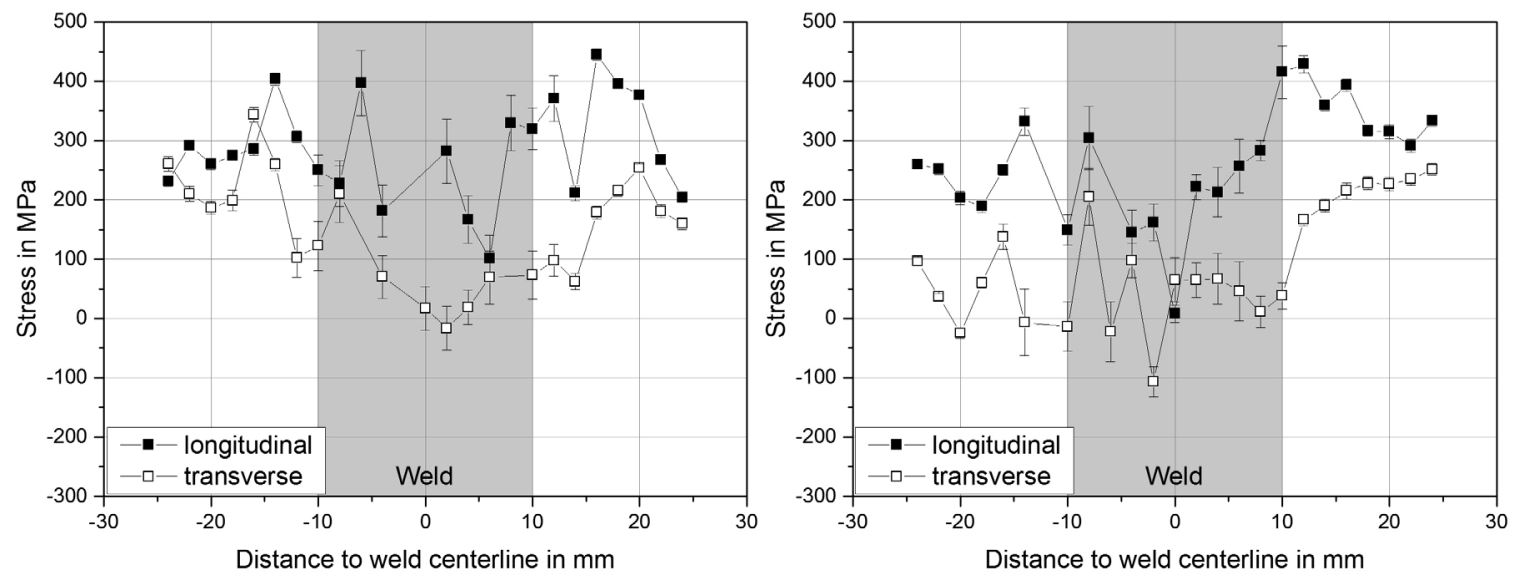

Figure 6: Longitudinal and transverse residual stresses after the $1^{\text {st }}$ repair cycle of S355 (left) and 5690 (left) 

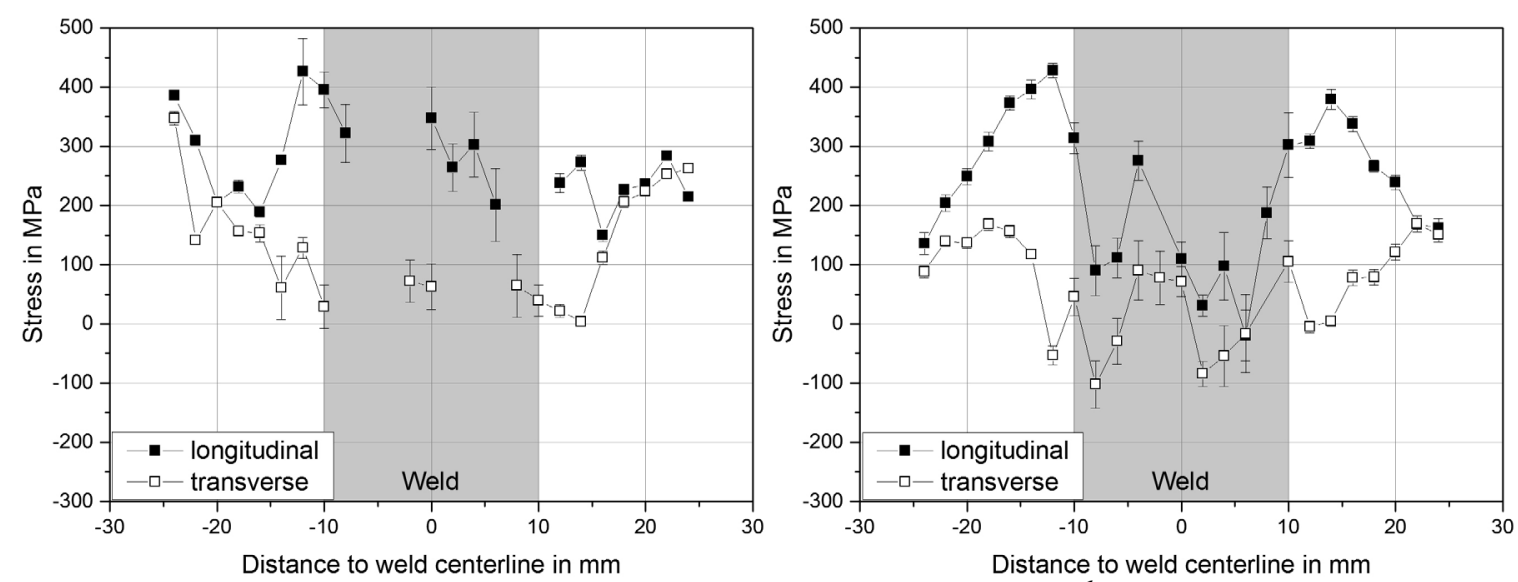

Figure 7: Longitudinal and transverse residual stresses after the $5^{\text {th }}$ repair cycle of S355 (left) and 5690 (right)

Adapting the welding procedure allowed control of the residual stress levels found after gouging and repeated deposition of the weld metal in the notch. Applying a Pilgrim-step sequence during welding (three steps) resulted in moderate stress levels longitudinal as well as transverse to the welding direction (Fig. 8). Even lower stresses than in the initial as welded condition were obtained. This applied for S355 as well as for S690. With shorter welds the shrinkage length was less. Therefore, longitudinal residual stresses were lower compared to the conventional welding procedure.
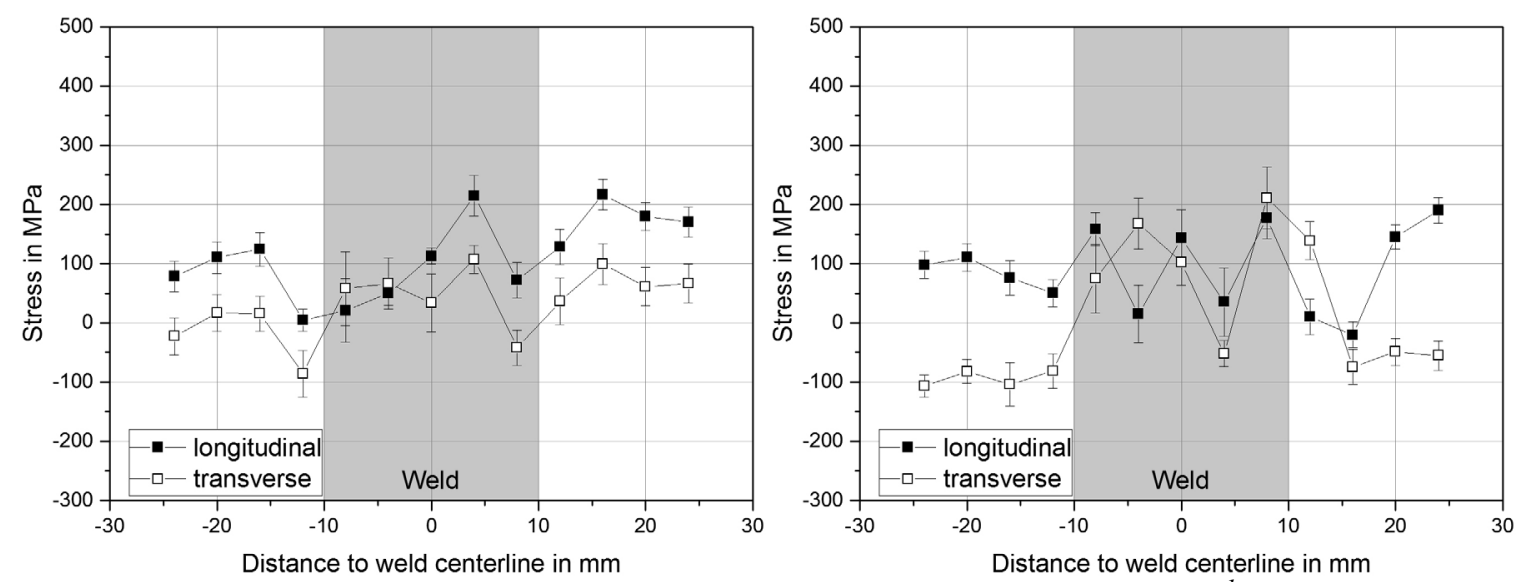

Figure 8: Longitudinal and transverse residual stresses after the $1^{\text {st }}$ (left) $5^{\text {th }}$ repair cycle (right) of 590 after applying back-step-repair welding.

\section{Summary}

Residual stresses were determined on welded samples of S355 and S690 high strength steel. The sample geometry represented a common detail used in bridge constructions. The residual stress state was analyzed by X-ray diffraction for the as welded condition and for subsequent first and fifth repair cycle. The residual stresses significantly increased after the first repair cycle and continued to increase with further weld repair cycles. The stress increase was more pronounced for the longitudinal direction. S355 was affected in both weld metal and HAZ, but the higher strength steel S690 was only influenced in the HAZ. The reason was the stress reduction due to solid state phase transformation acting in the weld metal, which was more prominent in case of S690. Elevated tensile residual stresses in the HAZ can become critical when the mechanical properties are degraded. 
Applying a Pilgrim-step sequence during the repair welding procedure is an appropriate way to reduce the residual stresses significantly.

\section{References}

[1] V.S. Miltyutin, The effect of arc-air cutting on the quality of metal, Welding Production 26 (1979) 44-46.

[2] Doshchechkina et al., Changes in the Structure of the surface zone in the air-cutting of metals, Welding Production 27 (1980) 40-42.

[3] K. Satoh, Y. Ueda, H. Kihara, Recent Trend of Researches on Restrain Stresses and Strains for Weld Cracking, Transactions of JWRI (1972) 53-68.

[4] K. Satoh, An Analytical Approach to the Problem of Restraint Intensity in Slit Weld. Transactions of JWRI (1972) 69-76.

[5] C. Schwenk, T. Kannengiesser, M. Rethmeier, Restraint Conditions and Welding Residual Stresses in Self-Restrained Cold Cracking Test, in: S.A. David, T. DebRoy, J.N. DuPont, T. Koseki, H.B. Smartt (Eds.), Trends in Welding Research. Proceedings of the 8th International Conference, 2009, pp. 766-773.

[6] Y. Ueda, K. Fukuda, Y.C. Kim, R. Koki, Characteristics of Restraint Stress-Strain of Slit Weld in a Finite Rectangular Plate and the Significance of Restraint Intensities as a Dynamical Measure, Transaction of JWRI 11 (1982) 105-113.

[7] Y. Ueda, K. Fukuda, I. Nishimura, H. Iiyama, N. Chiba, Cracking in welded corner joints. Metal Construction and British Welding Journal 1 (1984) 30-34.

[8] R.D. Stout, R. Vasudevan, W. Pense, A Field Weldability Test for Pipeline Steels, Welding Journal 55 (1976) 89-94.

[9] R. Vasudevan, R.D. Stout, W. Pense, A Field Weldability Test for Pipeline Steels - Part II, Welding Journal 59 (1980) 76-84.

[10] E. Macherauch and P. Müller, Das $\sin ^{2} \psi$ - Verfahren der röntgenographischen Spannungsmessung, Z. angew. Physik 13 (1961) 305-312 (in German).

[11]T. Nitschke-Pagel, H. Wohlfahrt, Residual Stresses in Welded Joints - Sources and Consequences, Mater. $\quad$ Sci. Forum 404-407 (2002) 215-226. http://dx.doi.org/10.4028/www.scientific.net/MSF.404-407.215 